\title{
Microstructure and magneto-dielectric properties of the chitosan/gelatin-YIG biocomposites
}

\author{
E. J. J. Mallmann ${ }^{1}$, J. C. Góes ${ }^{2}$, S. D. Figueiró ${ }^{2}$, N. M. P. S. Ricardo ${ }^{3}$, J. C. Denardin ${ }^{4}$, \\ A. S. B. Sombra ${ }^{2}$, F. J. N. Maia ${ }^{3}$, S. E. Mazzeto ${ }^{3}$, P. B. A. Fechine ${ }^{1 *}$ \\ ${ }^{1}$ Grupo de Química de Materiais Avançados (GQMAT)- Departamento de Química Analítica e Físico-Química, \\ Universidade Federal do Ceará - UFC, Campus do Pici, CP 12100, CEP 60451-970 Fortaleza - CE, Brazil \\ ${ }^{2}$ Laboratório de Telecomunicações e Ciência e Engenharia dos Materiais -(LOCEM) - Departamento de Física, \\ Universidade Federal do Ceará - UFC, Campus do Pici, CP 12100, CEP 60451-970 Fortaleza - CE, Brazil \\ ${ }^{3}$ Laboratório de Produtos e Tecnologia em Processos (LPT), Departamento de Química Orgânica e Inorgânica, \\ Universidade Federal do Ceará - UFC, Campus do Pici, CP 12100, CEP 60451-970 Fortaleza - CE, Brazil \\ ${ }^{4}$ Departamento de Física, Universidad de Santiago de Chile, USACH, Av. Ecuador 3493, Santiago, Chile
}

Received 24 March 2011; accepted in revised form 16 June 2011

\begin{abstract}
This work is devoted to the preparation of yttrium iron garnet (YIG) ferrimagnetic biocomposites based in biodegradable chitosan and gelatin. The aim was to produce composite films containing controlled amounts of YIG to obtain a new biological material with magneto-dielectric features. Structural characterization of the biocomposites was made by scanning electron microscopy, X-ray diffraction, infrared absorption spectroscopy and thermal analysis, while the dielectric and magnetic properties were obtained from dielectric spectroscopy and magnetic hysteresis loops, respectively. The versatility of the films obtained makes them possible candidates for use as biomaterials or electronic device.
\end{abstract}

Keywords: biocomposites, chitosan, gelatin, yttrium iron garne

\section{Introduction}

There are a lot of researches about association of the magnetic ceramics with biological material. Kim et al. [1] have obtained microspheres of $\mathrm{Fe}_{3} \mathrm{O}_{4}$ encapsulated with chitosan as a MRI image contrast, while Jain et al. [2] obtained magnetic nanoparticles coated with Oleic-Pluronic for sustained delivery of cancer agents. Matsumine et al. [3] have developed a novel hyperthermic treatment modality using magnetic materials (calcium phosphate cement containing $\mathrm{Fe}_{3} \mathrm{O}_{4}$ ) for metastatic bone tumors. In this sense, biological molecules are important to begin the magnetic component in a bio-inert composite. Chitosan is obtained from partial deacetylation of chitin. It is a very interesting polysaccharide which can be widely chemically modified on its amino and hydroxyl groups. It is promising in plastic products in the medical and food fields, due to the fact that it is a biodegradable, versatile and biocompatible polymer. The use of chitosan and its association to other materials to obtain biocomposites is widely shown in literature [4-8]. On the other hand, gelatin is a protein extracted from collagen. It is water soluble, also biodegradable and extremely biocompatible. Chitosan-gelatin blends are very interesting polymers, since a mixture of both does not result in a loss of their individual properties [9-13].

Yttrium iron garnet $\left(\mathrm{YIG}-\mathrm{Y}_{3} \mathrm{Fe}_{5} \mathrm{O}_{12}\right.$ ) is a ferrimagnetic particle that belongs to a family of complex oxides, the garnet. They are part of a family of materials that exhibit characteristic magnetic behavior. Their magnetic properties depend on the composi- 
tion (presence of magnetic ions), the crystal structure (the three-dimensional geometric arrangement of the ions) and temperature. These oxides have unique magnetic properties, magneto-optical, thermal, electrical and mechanical as well as ferrimagnetism, excellent resistance to radiation damage, high thermal conductivity, high electrical resistivity, controllable saturation magnetization and moderate thermal expansion coefficient [14-16].

Results about properties of the collagen/YIG biocomposite films were presented in previous studies [17]. In this work, a novel magnetic biocomposite with magneto-dielectric properties was obtained from chitosan and gelatin as polymeric matrix, crosslinked with glutaraldehyde and YIG as ferrimagnetic phase. Thus, the polymeric matrix was changed and the experimental procedures were improved to obtain a better quality of the biocomposites. These changes increased the YIG homogenate in biological matrix and modified the magnetic-dielectric behavior. The structural, dielectric and magnetic properties were investigated to characterize the material, applying techniques such as infrared spectroscopy, X-ray diffraction, scanning electron microscopy, thermogravimetric analysis, differential scanning calorimetry, dielectric and magnetic measurements.

\section{Material and methods}

\subsection{Ferrimagnetic particle}

The preparation of the ferrimagnetic particles was made reacting iron and yttrium oxides, where stoichiometric amount of $\mathrm{Y}_{2} \mathrm{O}_{3}(99.99 \%$, Aldrich) and $\mathrm{Fe}_{2} \mathrm{O}_{3}$ (99.00\%, Sigma-Aldrich, St. Louis, MO, USA) were used in the YIG preparation. The material was grounded on a Fritsch Pulverisette 6 (Fristsch $\mathrm{GmbH}$, Idar-Oberstein, Germany) planetary mill in sealed stainless steel vials $\left(221.69 \mathrm{~cm}^{3}\right)$ and balls $(\varnothing 10 \mathrm{~mm}$ ) under air in weight ratio 1/9 (wt. of mixture powder/wt. of balls). Mechanical alloying was performed for $1 \mathrm{~h}$ of milling with $370 \mathrm{rpm}$. After this, the powder was submitted to calcination in air at $1150^{\circ} \mathrm{C}$ for $5 \mathrm{~h}$. The reaction occurring during calcination can be summarized as per Equation (1):

$3 \mathrm{Y}_{2} \mathrm{O}_{3(\mathrm{~s})}+5 \mathrm{Fe}_{2} \mathrm{O}_{3(\mathrm{~s})} \rightarrow 2 \mathrm{Y}_{3} \mathrm{Fe}_{5} \mathrm{O}_{12(\mathrm{~s})}(\mathrm{YIG})$

\subsection{Chitosan and gelatin solutions}

Chitosan (PADETEC Fortaleza-Ceará-Brazil, DD = $80 \%)$ and gelatin $(99.00 \%$, VETEC, Xerém - Duque de Caxias - RJ) were dissolved into a $2 \% \mathrm{v} / \mathrm{v}$ acetic acid solution and centrifuged for $30 \mathrm{~min}$ at $900 \mathrm{rpm}$ until complete dissolution to obtain a $2 \% \mathrm{w} / \mathrm{v}$ solution of each one. Both solutions were mixed in a 1:1 proportion and centrifuged for $15 \mathrm{~min}$ at $5000 \mathrm{rpm}$ to obtain the chitosan-gelatin solution.

\subsection{Preparation of chitosan-gelatin-YIG films}

The YIG powder was dispersed in $50 \mathrm{ml}$ of chitosan-gelatin solution using a glass rod. The amount of YIG used was $250 \mathrm{mg}$ and $500 \mathrm{mg}$, respectively. A total of ten samples were prepared, where eight of those were cross-linked by $0.1 \%$ and $0.025 \% \mathrm{v} / \mathrm{v}$ glutaraldehyde (VETEC). The homogeneous emulsions were formatted into an acrylic mould and dried into a refrigerator. The samples were labeled as $F, F_{0.1}, F_{0.025}, F_{25}, F_{0.1} Y_{25}, F_{0.025} Y_{25}$, $\mathrm{FY}_{50}, \mathrm{FG}_{0.1} \mathrm{Y}_{50}$ and $\mathrm{FG}_{0.025} \mathrm{Y}_{50}$, where $\mathrm{FG}_{\mathrm{a}} \mathrm{Y}_{\mathrm{b}}$ can be read as $\mathrm{F}=$ film, $\mathrm{G}=$ glutaraldehyde, $\mathrm{Y}=\mathrm{YIG}$ and $a=$ glutaraldehyde concentration [\%] and $b=$ YIG weight used during the preparation (250 and $500 \mathrm{mg}$ ), as shown in Table 1. The effective YIG concentration on each composite was obtained by the relation between the residual and initial weight. The film thickness was measured using a Micrometer (Model 549E, Testing Machines Inc, Mineola, LI, $\mathrm{NY}$ ). The thickness measurements were taken at ten different points along the gauge length of each specimen and the meaningful values were taken.

Table 1. Composition and nomenclature of the samples

\begin{tabular}{|l|c|c|c|l|l|}
\hline \multirow{2}{*}{ \%G } & \multirow{2}{*}{$\begin{array}{c}\mathbf{V}_{\mathbf{G}} \\
\mathbf{m L} \mathbf{l}\end{array}$} & $\begin{array}{c}\mathbf{W}_{\mathbf{G}} \\
\mathbf{j m g}]\end{array}$ & \multirow{2}{*}{$\mathbf{F} / \mathbf{G}$} & \multicolumn{2}{|c|}{ Sample } \\
\cline { 5 - 6 } & & & $\mathbf{Y I G}_{\mathbf{( 5 0 0} \mathbf{~ m g}}$ & $\mathbf{Y I G}_{\mathbf{( 2 5 0} \mathbf{~ m g})}$ \\
\hline 0.0 & - & - & 0 & $\mathrm{FY}_{50}$ & $\mathrm{FY}_{25}$ \\
\hline 0.1 & 0.20 & 50 & $20: 1$ & $\mathrm{FG}_{0.1} \mathrm{Y}_{50}$ & $\mathrm{FG}_{0.1} \mathrm{Y}_{25}$ \\
\hline 0.075 & 0.15 & 37.5 & $26.6: 1$ & $\mathrm{FG}_{0.075} \mathrm{Y}_{50}$ & $\mathrm{FG}_{0.075} \mathrm{Y}_{25}$ \\
\hline 0.050 & 0.10 & 25 & $40: 1$ & $\mathrm{FG}_{0.050} \mathrm{Y}_{50}$ & $\mathrm{FG}_{0.050} \mathrm{Y}_{25}$ \\
\hline 0.025 & 0.05 & 12.5 & $80: 1$ & $\mathrm{FG}_{0.025} \mathrm{Y}_{50}$ & $\mathrm{FG}_{0.025} \mathrm{Y}_{25}$ \\
\hline
\end{tabular}

$G=$ glutaraldehyde; $V_{\mathrm{G}}=$ glutaraldehyde volume; $W_{\mathrm{G}}=$ glutaraldehyde weight; $F=$ chitosan-gelatin $1: 1$ film; $F / G=$ ratio of film/glutaraldehyde weight; $\mathrm{Y}=$ YIG

\subsection{Scanning electron microscopy}

Micrographs of magnetic biocomposites were obtained by scanning electron microscope (SEM) (Vega XMU/Tescan, Bruker (Billerica, MA, USA)), 
operating with bunches of primary electrons ranging from 12 to $30 \mathrm{keV}$ of $5.0 \mathrm{~mm} \times 5.0 \mathrm{~mm}$ square samples. The samples were covered with a $90 \mathrm{~nm}$ gold powder layer.

\subsection{X-ray diffraction}

A Rigaku (Tokyo, Japan) X-ray powder diffractometer operating on $40 \mathrm{kV} / 30 \mathrm{~mA}$ with a $\mathrm{Cu}-\mathrm{K}_{\alpha \mathrm{I}}$ tube $(\lambda=1.54056 \AA)$ was used to obtain the $\mathrm{X}$-ray diffraction pattern of the ferrimagnetic biocomposites. The diffraction patterns were carried out using Bragg-Brentano geometry in continuous mode with speed of $0.5^{\circ} / \mathrm{min}$ and step size of $0.02^{\circ}(2 \theta)$ in the angular range $20-60^{\circ}(2 \theta)$.

\subsection{FT-IR spectroscopy}

Infrared (IR) spectra were recorded using a VERTEX 70 (BRUKER, Billerica, MA, USA) spectrophotometer. The samples were prepared be freezing at liquid nitrogen and mixing with $\mathrm{KBr}$ pastilles. The region analyzed was between $400-1800 \mathrm{~cm}^{-1}$.

\subsection{Thermogravimetric analysis}

Thermogravimetric analyses (TGA) were performed using a Mettler Toledo (Zürich, Switzerland) TGA/ SDTA $851^{\mathrm{e}}$, equipped with a micro-balance. The rate was $10^{\circ} \mathrm{C} / \mathrm{min}(50 \mathrm{ml} / \mathrm{min}$ flow $)$ in a dynamic $\mathrm{N}_{2}$ atmosphere. Each sample was sealed in an aluminum pan and heated from 25 to $900^{\circ} \mathrm{C}$ temperatures.

\subsection{Differential scanning calorimetry}

Differential scanning calorimetry was carried out using NETZSCH (Selb, Germany) DSC 204 F1Phoenix ${ }^{\circledR}$ equipment. Accurately weighed $5 \mathrm{mg}$

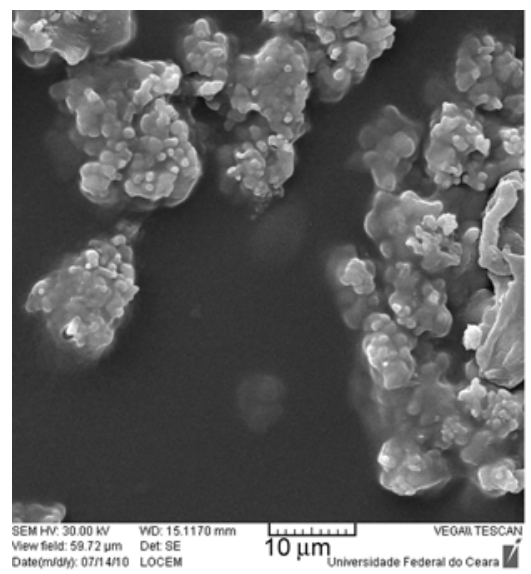

a) dried material was placed in an aluminum cup and hermetically sealed. An empty cup was used as reference. Samples were analyzed under continuous flow of dry nitrogen gas at a heating rate of $10^{\circ} \mathrm{C} \cdot \mathrm{min}^{-1}$ from 25 to about $300^{\circ} \mathrm{C}$.

\subsection{Dielectric and magnetic measurements}

Dielectric measurements: real $\left(\varepsilon_{\mathrm{r}}^{\prime}\right)$ parts of relative permittivity and loss tangent $\left(\tan \delta=\varepsilon^{\prime \prime}{ }_{\mathrm{r}} / \varepsilon_{\mathrm{r}}^{\prime}\right)$ were performed using an Agilent (Santa Clara, CA, USA) 4991 A RF impedance material analyzer. It covered the region of $10 \mathrm{MHz}-1 \mathrm{GHz}$ at room temperature $(300 \mathrm{~K})$. The magnetization measurements were performed at room temperature with a magnetometer VSM (vibrating sample magnetometer) previously calibrated with Ni wire. The magnitude of magnetization was given in $\mathrm{emu} / \mathrm{g}$.

\section{Results and discussion}

The SEM was performed to investigate the interaction between the polymeric matrix and the ceramic. The samples $\mathrm{FY}_{25}, \mathrm{FG}_{0.1} \mathrm{Y}_{25}, \mathrm{FY}_{50}$ and $\mathrm{FG}_{0.1} \mathrm{Y}_{50}$ were chosen to represent the behavior of all the system and they are shown in Figures 1a and b, and Figures $2 \mathrm{a}$ and $\mathrm{b}$, respectively. The amount of YIG present in series prepared with $500 \mathrm{mg}$ of YIG is higher than the $250 \mathrm{mg}$ ones, as revealed in Figures 1a and 2a, and as shown in thermogravimetric analysis. It is possible to observe that the polymeric matrix in $250 \mathrm{mg}$ series is larger, and the grains are deeply encapsulated on it, while in $500 \mathrm{mg}$ series the amount of YIG particles is outside the membrane. When the blend received the glutaraldehyde treatment, the YIG particles were encapsulated by polymeric matrix, and YIG was found only in cer-

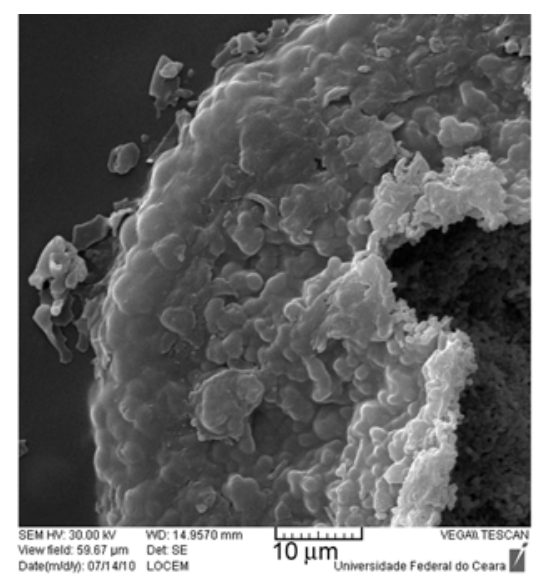

b)

Figure 1. Scanning electron photomicrograph of $\mathrm{FY}_{25}$ (a) and $\mathrm{FG}_{0.1} \mathrm{Y}_{25}$ (b) at $2500 \times$ 


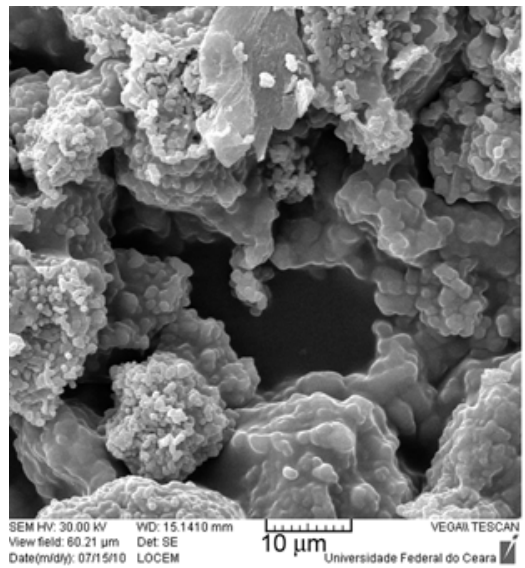

a)

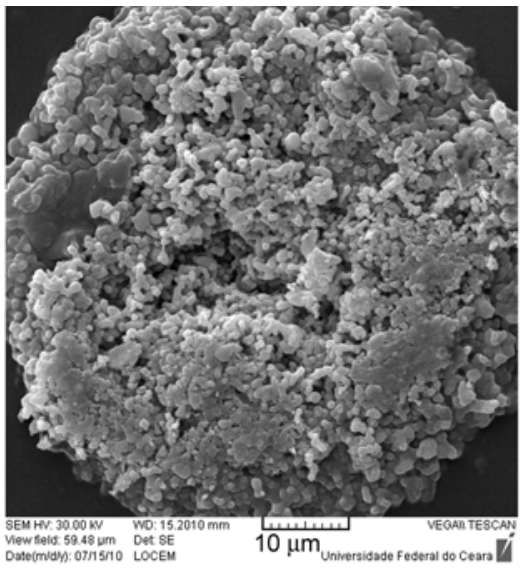

b)

Figure 2. Scanning electron photomicrograph of $\mathrm{FY}_{50}$ (a) and $\mathrm{FG}_{0.1} \mathrm{Y}_{50}$ (b) at $2500 \times$

tain places, causing an extrusion within the composite, as shown in Figures $1 \mathrm{~b}$ and $2 \mathrm{~b}$.

Figure 3 shows the XRD patterns of the samples $F$ (only chitosan and gelatin), $\mathrm{FY}_{25}, \mathrm{FY}_{50}$ and YIG. The crystalline phase obtained from the YIG powder was identified by comparing the diffractograms from the ICDD database (ICDD/PDF-70-0953), see Figure 3. One can observe in F sample an amorphous phase characteristic to the matrix polymer and this pattern follows those observed in the literature [18-22]. This behavior is present in all com-

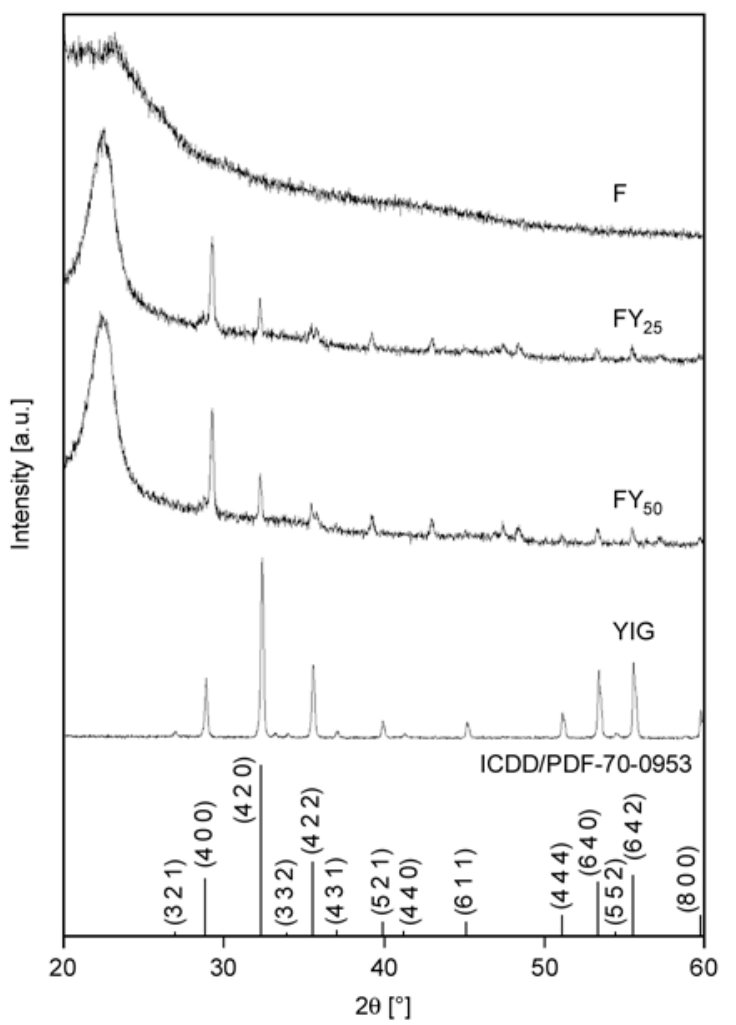

Figure 3. XRPD patterns of the ferrimagnetic phase (YIG), $\mathrm{F}$ and their composites $\left(\mathrm{FY}_{25}\right.$ and $\left.\mathrm{FY}_{50}\right)$ posites, see $\mathrm{FY}_{25}$ and $\mathrm{FY}_{50}$ (Figure 3). The broad peak in composites at $2 \theta=32.2^{\circ}$ happened due to the association of the chitosan-gelatin with YIG particles. When we observe the composites containing YIG, some peaks appears to be dislocated, according to Figure 3 . The peak of YIG crystal at $2 \theta=28.9^{\circ}$ is increased when compared to others. While some peaks appear enlarged due to the alignment of their plane with the polymer, others showed an attenuation of their intensity due to a non-alignment plane with the organic phase that scatters Xrays, where the crystalline phase had reduced the intensity of its peak. The peaks in $2 \theta=28.9,45.16$ and $51.12^{\circ}$ were shifted when observed in the composite. These displacements are due to the fact that the sample is not completely flat and there was the influence of conformation on the incidence of Xrays in the region between $2 \theta=28.9$ and 51.12.

The IR spectrum of the $\mathrm{F}, \mathrm{FG}_{0.1}$ and $\mathrm{FY}_{50}$ samples are illustrated in Figure 4. One can observe an absorption band in the region of $1641-1630 \mathrm{~cm}^{-1}$, characteristic of the stretching of the $\mathrm{C}=\mathrm{O}$ group of acetamide of chitosan, which characterizes its partial deacetylation. It is likely that the band on the imine bond $(\mathrm{C}=\mathrm{N})$, formed from the cross-linking with glutaraldehyde, is superimposed on the $\mathrm{C}=\mathrm{O}$ group of chitosan acetamide, since both absorb in the same region of the infrared spectrum. The band shown at $1544-1537 \mathrm{~cm}^{-1}$ refers to the $\mathrm{C}-\mathrm{N}$ bond (amide II), whereas in $1238 \mathrm{~cm}^{-1}$ there is a characteristic absorption band of the $\mathrm{C}-\mathrm{N}$ bond of amide III. Both bands are referred to peptide bonds of gelatin. The absorption band at $1400 \mathrm{~cm}^{-1}$ existing features the $\mathrm{C}-\mathrm{N}$ bond of proline, amino acid of gelatin. In 


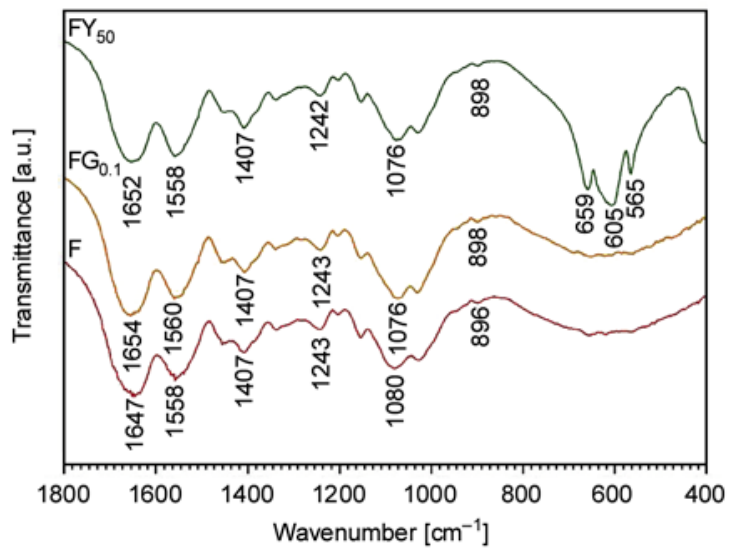

Figure 4. Infrared spectroscopy of the $\mathrm{F}, \mathrm{FG}_{0.1}$ and $\mathrm{FY}_{50}$ composites

$1072-1062 \mathrm{~cm}^{-1}$ there is an absorption band which is typical of stretch of the connecting piranosydic rings of chitosan $(\mathrm{C}-\mathrm{O}-\mathrm{C})$. The region of 1200 $800 \mathrm{~cm}^{-1}$ shows characteristic absorption bands of saccharides structures. The YIG is characterized by absorption bands exist at 565, 605 and $659 \mathrm{~cm}^{-1}$. These bands are assigned to $\mathrm{Fe}-\mathrm{O}$ bonds. The bands

Table 2. Infrared wavenumbers and assignments

\begin{tabular}{|c|c|c|}
\hline Sample & Wavenumbers $\left[\mathrm{cm}^{-1}\right]$ & Assignments \\
\hline \multirow{6}{*}{$\mathrm{F}$} & 1647 & $v(-\mathrm{C}=\mathrm{O})$ \\
\hline & 1558 & $v(-\mathrm{NHC}=\mathrm{O})$ \\
\hline & 1407 & $v(-\mathrm{C}-\mathrm{N})$ \\
\hline & 1243 & $v\left(-\mathrm{NH}_{2}\right)$ \\
\hline & 1080 &.$v(-\mathrm{C}-\mathrm{OH})$ \\
\hline & 896 & $\sigma(-\mathrm{CH})$ \\
\hline \multirow{6}{*}{$\mathrm{FG}_{0.1}$} & 1654 & $v(-\mathrm{C}=\mathrm{O})$ \\
\hline & 1560 & $v(-\mathrm{NHC}=\mathrm{O})$ \\
\hline & 1407 & $v(-\mathrm{C}-\mathrm{N})$ \\
\hline & 1243 & $v\left(-\mathrm{NH}_{2}\right)$ \\
\hline & 1076 &.$v(-\mathrm{C}-\mathrm{OH})$ \\
\hline & 898 & $\sigma(-\mathrm{CH})$ \\
\hline \multirow{9}{*}{$\mathrm{FY}_{25}$} & 1652 & $v(-\mathrm{C}=\mathrm{O})$ \\
\hline & 1558 & $v(-\mathrm{NHC}=\mathrm{O})$ \\
\hline & 1407 & $v(-\mathrm{C}-\mathrm{N})$ \\
\hline & 1242 & $v\left(-\mathrm{NH}_{2}\right)$ \\
\hline & 1076 &.$v(-\mathrm{C}-\mathrm{OH})$ \\
\hline & 898 & $\sigma(-\mathrm{CH})$ \\
\hline & 659 & $v(\mathrm{Fe}-\mathrm{O})$ \\
\hline & 605 & $v(\mathrm{Fe}-\mathrm{O})$ \\
\hline & 565 & $v(\mathrm{Fe}-\mathrm{O})$ \\
\hline
\end{tabular}

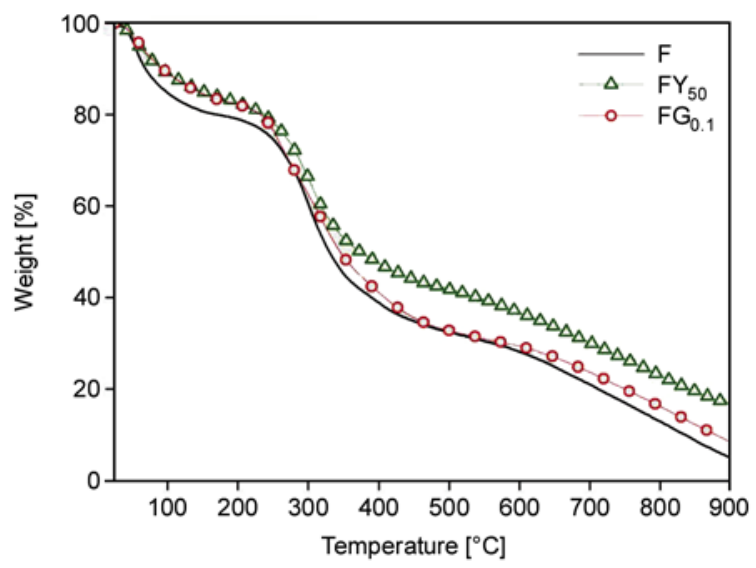

Figure 5. Thermogravimetric analysis of $\mathrm{F}, \mathrm{FG}_{0.1}$ and $\mathrm{FY}_{50}$ composites

obtained in the analysis were conferred with the literature data [23-27] and are shown in Table 2.

The thermogravimetric analysis was performed to obtain the degradation profile of samples as well as to identify the mass of residual YIG and help to explain the dielectric and magnetic results. Figure 5 shows the degradation curves while Table 3 illustrates the events of degradation for the samples. The mass of each sample was fixed in $5.00 \mathrm{mg}$. Three samples were chosen: the composite without YIG and glutaraldehyde (F), the one without YIG and cross-linked with glutaraldehyde $0.1 \%\left(\mathrm{FG}_{0.1}\right)$ and the sample containing $500 \mathrm{mg}$ of YIG. Samples cross-linked with $0.1 \%$ glutaraldehyde had more waste $(0.429 \mathrm{mg})$ compared to non cross-linked that left $0.254 \mathrm{mg}$, as well as those containing a greater mass of YIG on its constitution also left a larger residual mass according to the values shown in Table 3. The higher residue in $\mathrm{FY}_{50}, 0.843 \mathrm{mg}$ is attributed to the presence of ceramic in the composite, which is more resistant to the thermal treatment than other films, according the Table 3, where the events of degradation show the higher intervals, $25-181^{\circ} \mathrm{C}$ as first event and started at $247^{\circ} \mathrm{C}$ on second event. Comparing the two samples without YIG, the sample cross-linked with glutaraldehyde left more residues than $\mathrm{F}$ sample, because of the larger

Table 3. Samples degradation events

\begin{tabular}{|l|l|l|l|l|l|l|l|}
\hline \multirow{2}{*}{ Sample } & \multicolumn{3}{|c|}{$\mathbf{1}^{\text {st }}$ event } & \multicolumn{2}{|c|}{$\mathbf{2}^{\text {nd }}$ event } & \multirow{2}{*}{$\mathbf{M}^{\mathbf{R}}$} & \multirow{2}{*}{$\mathbf{M}$} \\
\cline { 2 - 8 } & $\mathbf{M}^{\mathbf{I}}$ & $\mathbf{T}^{\mathbf{G}}$ & $\mathbf{W}^{\mathbf{L}}$ & $\mathbf{T}^{\mathbf{G}}$ & $\mathbf{W}^{\mathbf{L}}$ & & 0.254 \\
\hline $\mathrm{F}$ & 5.0 & $25-177$ & 20.23 & $201-452$ & 43.76 & 5.08 & 0.429 \\
\hline $\mathrm{FG}_{0.1}$ & 5.0 & $25-173$ & 16.80 & $201-472$ & 48.21 & 8.58 & 0.843 \\
\hline $\mathrm{FY}_{50}$ & 5.0 & $25-181$ & 16.49 & $247-497$ & 36.04 & 16.87 & \\
\hline
\end{tabular}

$M^{\mathrm{I}}$ - initial mass [mg)], $W^{\mathrm{L}}-$ weight loss [\%], $T^{\mathrm{G}}-$ event temperature gap [ $\left.{ }^{\circ} \mathrm{C}\right], M^{\mathrm{R}}-$ mass residues [\%] and $M-\operatorname{mass}$ residues [mg] 


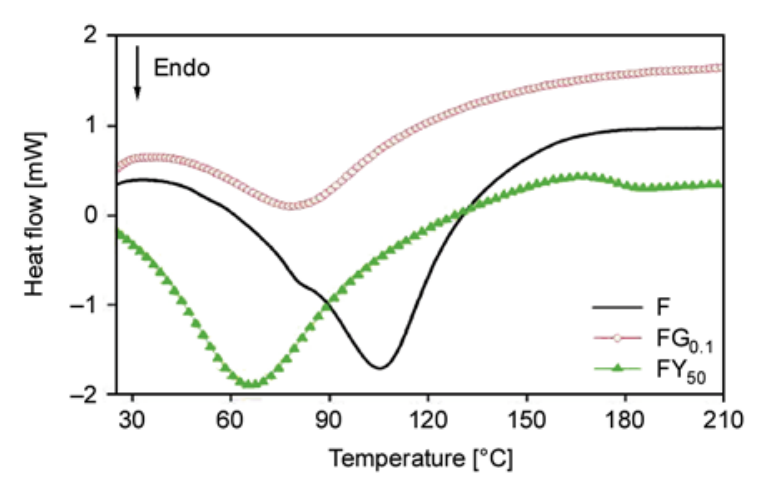

Figure 6. Differential scanning calorimetry of $\mathrm{F}, \mathrm{FG}_{0.1}$ and $\mathrm{FY}_{50}$ composites

chains formed by incorporation of the aldehyde into the gelatin-chitosan composite.

The DSC scans in Figure 6 show that polymeric matrix of all samples is characterized by an endothermic peak. It is due to the denaturation process of gelatin and chitosan molecules and it is hydration dependant. For chitosan-gelatin film, the denaturation temperature is $105.4^{\circ} \mathrm{C}$. When it is crosslinked with glutaraldehyde, $\mathrm{FG}_{0.1}$, the temperature decreases to $78.5^{\circ} \mathrm{C}$, but the lower denaturation temperature is observed at $65.01^{\circ} \mathrm{C}$, in the $\mathrm{FY}_{50}$ sample. These results show that YIG addition decreases considerably the thermal stability of the polymeric matrix, while $\mathrm{FG}_{0.1}$ shows a slight decrease, comparing to the $\mathrm{F}$ sample. These results may be related to the shrinkage of the chitosan-gelatin matrix that is observed macroscopically.

The obtained data from dielectric spectroscopy are shown in Figure 7. The values of $\varepsilon_{r}^{\prime}$ decreased with the increase of frequency. Table 4 illustrates dielectric properties at 10,100 and $1000 \mathrm{MHz}$ frequencies. The sample $\mathrm{FG}_{0.1}$ showed the higher $\varepsilon_{\mathrm{r}}^{\prime}$ values, while $\mathrm{FG}_{0.025} \mathrm{Y}_{50}$ the lower. The samples without YIG had shown the higher $\varepsilon_{\mathrm{r}}^{\prime}$ values, which are higher values than polymeric compounds in literature [28-31]. According to Fechine et al. [32], YIG has $\varepsilon_{\mathrm{r}}^{\prime}$ near to 7.6 at 10,100 and $1000 \mathrm{MHz}$, with a $\tan \delta$ of 0.0602 ,

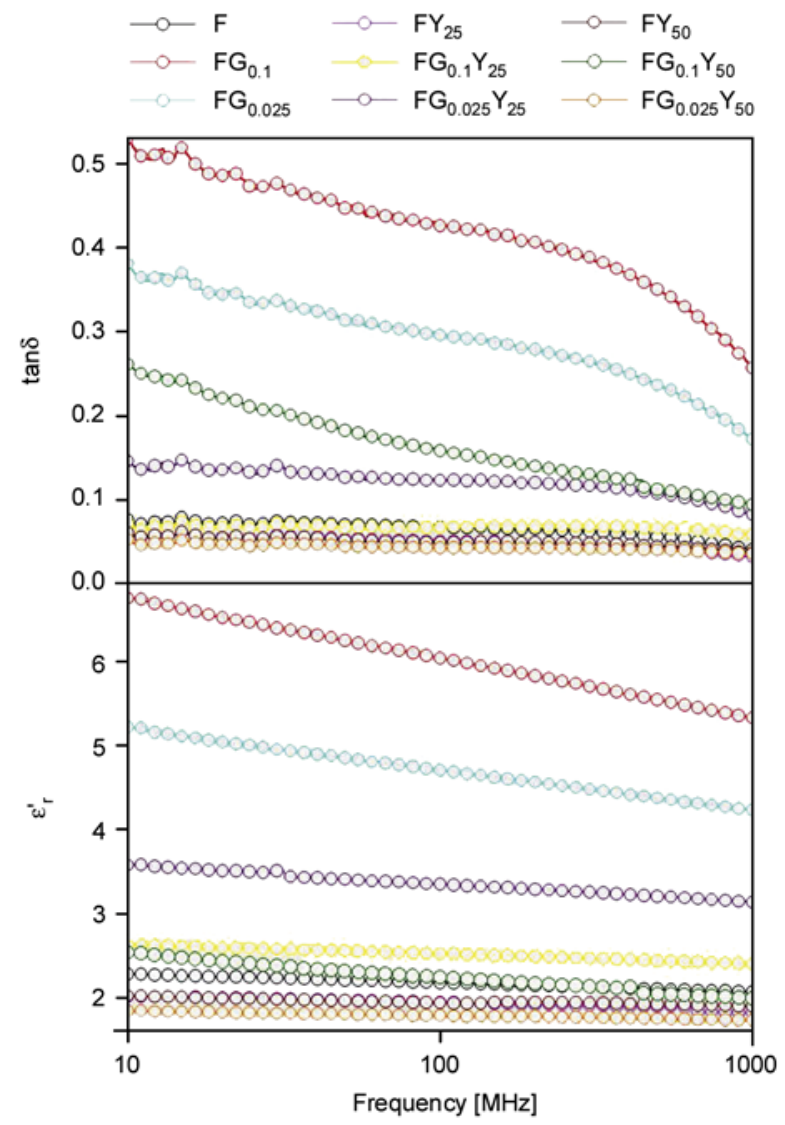

Figure 7. Dielectric spectroscopy measurements

0.0132 and 0.0032 , respectively. The addition of YIG to polymeric matrix has not resulted in a composite with higher values to $\varepsilon^{\prime}$, however the decrease of $\tan \delta$ is observed. It was not detected dielectric relaxation process in this frequency range for dielectric $\left(\varepsilon_{\mathrm{r}}^{\prime}\right.$ and $\left.\tan \delta\right)$ measurements. Thus, these biocomposites have a moderate dielectric stability in the analyzed range frequency. The YIG stability along the frequency analyzed is a characteristic that may be incorporated to the composites. The literature data report cases of increase [33] and decrease [18] of the $\varepsilon_{\mathrm{r}}^{\prime}$, depending on the cross-linker agent and the polymeric material employed. This happens due to density, that is dependent on the material

Table 4. Films thickness, permittivity dielectric and loss tangent values of the biocomposites

\begin{tabular}{|c|c|c|c|c|c|c|c|}
\hline \multirow{2}{*}{ Sample } & \multirow{2}{*}{$\begin{array}{c}\text { Thickness } \\
{[\mu \mathrm{m}]}\end{array}$} & \multicolumn{2}{|c|}{$10 \mathrm{MHz}$} & \multicolumn{2}{|c|}{$100 \mathrm{MHz}$} & \multicolumn{2}{|c|}{$1 \mathrm{GHz}$} \\
\hline & & $\varepsilon_{r}^{\prime}$ & $\tan \delta$ & $\varepsilon_{\mathrm{r}}^{\prime}$ & $\tan \delta$ & $\varepsilon_{r}^{\prime}$ & $\tan \delta$ \\
\hline $\mathrm{F}$ & 139 & 2.273 & 0.075 & 2.174 & 0.067 & 2.066 & 0.041 \\
\hline $\mathrm{FG}_{0.1}$ & 184 & 6.748 & 0.525 & 6.029 & 0.385 & 5.319 & 0.255 \\
\hline $\mathrm{FG}_{0.025}$ & 173 & 5.207 & 0.378 & 4.696 & 0.295 & 4.224 & 0.171 \\
\hline $\mathrm{FY}_{25}$ & 155 & 2.011 & 0.059 & 1.944 & 0.051 & 1.821 & 0.032 \\
\hline $\mathrm{FG}_{0.1} \mathrm{Y}_{25}$ & 214 & 2.621 & 0.070 & 2.520 & 0.067 & 2.397 & 0.058 \\
\hline $\mathrm{FG}_{0.025} \mathrm{Y}_{25}$ & 193 & 3.572 & 0.143 & 3.344 & 0.123 & 3.131 & 0.082 \\
\hline $\mathrm{FY}_{50}$ & 179 & 2.025 & 0.060 & 1.936 & 0.049 & 1.894 & 0.037 \\
\hline $\mathrm{FG}_{0.1} \mathrm{Y}_{50}$ & 163 & 2.531 & 0.259 & 2.236 & 0.158 & 1.992 & 0.094 \\
\hline $\mathrm{FG}_{0.025} \mathrm{Y}_{50}$ & 193 & 1.848 & 0.051 & 1.783 & 0.042 & 1.726 & 0.036 \\
\hline
\end{tabular}


porosity, i.e., when material has a large number of vacancies, the $\varepsilon_{\mathrm{r}}^{\prime}$ decreases to minor values due to air amount in the composite. The cross-linking changes the charges' movement on the dielectric material, promoting the formation of new covalent bonds, hydrogen bonds and Van der Waals interactions [33]. It can be observed in the sample $\mathrm{F}$ that, when crosslinked with glutaraldehyde $0.1 \%$, the value of dielectric constant increases. This shows that the dielectric is also an intrinsic behavior of the material, depending on the distribution of charges and electronic density.

The curves of Figures $8 \mathrm{a}$ and $8 \mathrm{~b}$ show the profile of magnetization (M) as a function of applied magnetic field (H). Fechine et al. identified that the subnets of the shells can be represented by $\left\{\cdot \overrightarrow{\mathrm{R}}_{3}\right\}\left[\overrightarrow{\mathrm{Fe}}_{2}\right]\left(\breve{\mathrm{Fe}}_{3}\right)$ where \{\}$,[]$ and () indicate occupation dodecahedral, octahedral and tetrahedral, respectively [32]. Arrows show the relative orientations of magnetic moments. Most interaction is $\left[\overrightarrow{\mathrm{Fe}}_{2}\right]\left({ }^{\mathrm{F} \mathrm{Fe}_{3}}\right)$, since the rare earth cations are large and very weakly engaged with the subnets of iron. The profile of magnetization shown in Figures 8a and $b$ suggest the obtaining of a soft ferrimagnetic composite, because the samples are very sensitive to an external magnetic field and reached their saturation magnetization $\left(\mathrm{M}_{\mathrm{S}}\right)$ with application of relatively small magnetic fields. The hysteresis can be caused by some of these phenomena [34]: interac- tions between the fields, anisotropy, strength of internal friction caused by the interstices, dislocations, impurities etc. Rajendran et al. [35], studying the effects of the magnetic properties of YIG as a function of particle size, observed that samples with approximately $25 \mathrm{~nm}$ still show magnetic saturation. However, they reported that below this value, the YIG can increase their magnetization with increasing field, without any magnetic hysteresis appearing, being a typical case of superparamagnetic behavior. Table 5 contains the hysteresis data for the samples, where remanent magnetization $\left(\mathrm{M}_{\mathrm{r}}\right)$ and coercive field $\left(\mathrm{H}_{\mathrm{c}}\right)$ were obtained from in-set figures in Figures $8 a$ and $b$. It is possible to observe a small hysteresis in these samples due them being soft ferrimagnetic. The general behavior of the obtained composite is similar to a collagen-YIG composite, according to Figueiró et al. [17].

It was added $250 \mathrm{mg}\left(\mathrm{FY}_{25}, \mathrm{FG}_{0.025} \mathrm{Y}_{25}\right.$ and $\left.\mathrm{FG}_{0.1} \mathrm{Y}_{25}\right)$ and $500 \mathrm{mg}\left(\mathrm{FY}_{50}, \mathrm{FG}_{0.025} \mathrm{Y}_{50}\right.$ and $\left.\mathrm{FG}_{0.1} \mathrm{Y}_{50}\right)$ of the YIG in the samples. However, the magnetic properties obtained for each group were slightly different due to the composition of the material. For example, $\mathrm{FY}_{50}$ presented high value of $\mathrm{M}_{\mathrm{S}}$ than $\mathrm{FY}_{25}$ due to YIG amount in the composition. When the glutaraldehyde quantity added is analyzed, one can observe that $\mathrm{FG}_{0.1} \mathrm{Y}_{25}$ and $\mathrm{FG}_{0.025} \mathrm{Y}_{50}$ have the major values. In this case, there is an ideal composition of biopolymers (chitosan and gelatin) and glutaralde-

Table 5. Properties obtained from hysteresis data

\begin{tabular}{|l|c|c|c|c|c|c|}
\hline & $\mathbf{F Y}_{\mathbf{2 5}}$ & $\mathbf{F G}_{\mathbf{0 . 0 2 5}} \mathbf{Y}_{\mathbf{2 5}}$ & $\mathbf{F G}_{\mathbf{0 . 1}} \mathbf{Y}_{\mathbf{2 5}}$ & $\mathbf{F Y}_{\mathbf{5 0}}$ & $\mathbf{F G}_{\mathbf{0 . 0 2 5}} \mathbf{Y}_{\mathbf{5 0}}$ & $\mathbf{F G}_{\mathbf{0 . 1}} \mathbf{Y}_{\mathbf{5 0}}$ \\
\hline$H_{\mathrm{c}}[\mathrm{Oe}]$ & 14 & 15 & 14 & 16 & 14 & 14 \\
\hline$M_{\mathrm{r}}[\mathrm{emu} / \mathrm{g}]$ & 0.17 & 0.27 & 0.21 & 0.46 & 0.32 & 0.21 \\
\hline$M_{\mathrm{s}}[\mathrm{emu} / \mathrm{g}]$ & 2.63 & 2.39 & 3.18 & 5.53 & 4.73 & 3.18 \\
\hline
\end{tabular}
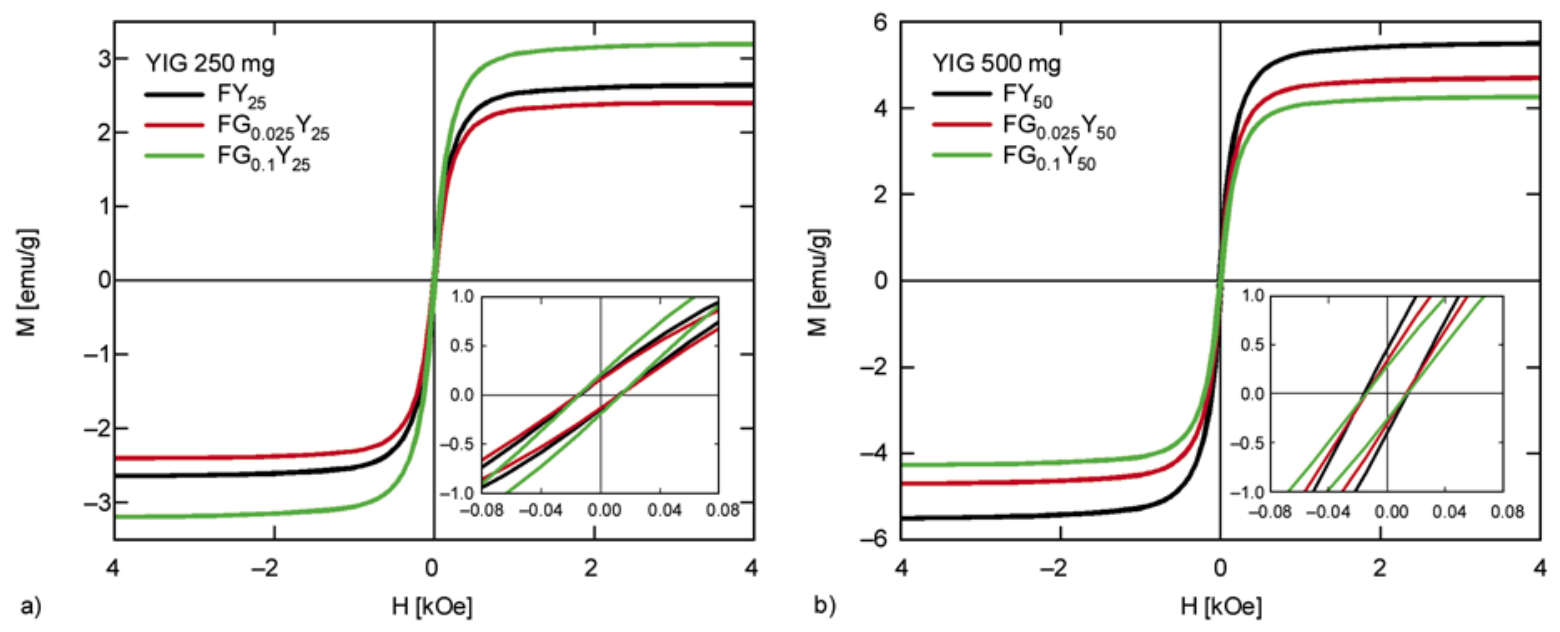

Figure 8. Magnetic measurements of (a) $250 \mathrm{mg}$-YIG series and (b) $500 \mathrm{mg}$-YIG series 
hyde to attach YIG to the film to obtain higher $\mathrm{M}_{\mathrm{S}}$. Thus, the magnetic-dielectric properties of these biocomposites are modified as a function of the quantity of each component in the system due to interactions between biopolymers, crosslinking agent and magnetic ferrite.

\section{Conclusions}

The results of this study suggest that a ferrimagnetic garnet and polymeric fiber (chitosan and gelatin) can be used to obtain a well distributed composite, where YIG particles were densely found into the polymeric matrix. This composite shows variable magnetic properties and values of dielectric constant according its constitution. These new biocomposites may be employed as a versatile material, due to its biocompatibility, flexibility, biodegradability and magnetic features.

\section{Acknowledgements}

Thanks to X-Ray Laboratory (Department of Physics UFC). Núcleo Milenio Magnetismo Básico y Aplicado and Proyecto BASAL FB0807 (Chilean agencies). This work was supported by CAPES, Funcap and CNPq (Brazilian agencies).

\section{References}

[1] Kim E. H., Ahn Y., Lee H. S.: Biomedical applications of superparamagnetic iron oxide nanoparticles encapsulated within chitosan. Journal of Alloys and Compounds, 434-435, 633-636 (2007). DOI: $10.1016 /$ j.jallcom.2006.08.311

[2] Jain T. K., Morales M. A., Sahoo S. K., Leslie-Pelecky D. L., Labhasetwar V.: Iron oxide nanoparticles for sustained delivery of anticancer agents. Molecular Pharmaceutics, 2, 194-205 (2005). DOI: $10.1021 / \mathrm{mp} 0500014$

[3] Matsumine A., Kusuzaki K., Matsubara T., Shintani K., Satonaka H., Wakabayashi T., Miyazaki S., Morita K., Takegami K., Uchida A.: Novel hyperthermia for metastatic bone tumors with magnetic materials by generating an alternating electromagnetic field. Clinical and Experimental Metastasis, 24, 191-200 (2007). DOI: $10.1007 / \mathrm{s} 10585-007-9068-8$

[4] El Badawy M.: Chemical modification of chitosan: Synthesis and biological activity of new heterocyclic chitosan derivatives. Polymer International, 57, 254261 (2008).

DOI: $10.1002 /$ pi.2333
[5] Chan P., Kurisawa M., Chung J. E., Yang Y-Y.: Synthesis and characterization of chitosan- $g$-poly(ethylene glycol)-folate as a non-viral carrier for tumor-targeted gene delivery. Biomaterials, 28, 540-549 (2007). DOI: 10.1016/j.biomaterials.2006.08.046

[6] Chen R-N., Wang G-M., Chen C-H., Ho H-O., Sheu M-T.: Development of N,O-(carboxymethyl)chitosan/ collagen matrixes as a wound dressing. Biomacromolecules, 7, 1058-1064 (2006).

DOI: $10.1021 / \mathrm{bm} 050754 \mathrm{~b}$

[7] Eweis M., Elkholy S. S., Elsabee M. Z.: Antifungal efficacy of chitosan and its thiourea derivatives upon the growth of some sugar-beet pathogens. International Journal of Biological Macromolecules, 38, 1-8 (2006).

DOI: 10.1016/j.ijbiomac.2005.12.009

[8] Ding P., Huang K-L., Li G-Y., Liu Y-F.: Preparation and properties of modified chitosan as potential matrix materials for drug sustained-release beads. International Journal of Biological Macromolecules, 41, 125131 (2007).

DOI: $10.1016 /$ j.ijbiomac.2006.12.008

[9] Asghar A., Henrickson R. L.: Chemical, biochemical, functional, and nutritional characteristics of collagen in food systems. Advances in Food Research, 28, 231372 (1982).

DOI: $10.1016 / \mathrm{S} 0065-2628(08) 60113-5$

[10] Farrugia C. A., Farrugia I. V., Groves M. J.: Comparison of the molecular weight distribution of gelatin fractions by size-exclusion chromatography and light scattering. Pharmacy and Pharmacology Communications, 4, 559-562 (1998).

DOI: 10.1111/j.2042-7158.1998.tb00675.x

[11] Saddler J. M., Horsey P. J.: The new generation gelatins: A review of their history, manufacture and properties. Anaesthesia, 42, 998-1004 (1987). DOI: $10.1111 / \mathrm{j} .1365-2044.1987 . t b 05376 . x$

[12] Courts A.: The N-terminal amino acid residues of gelatin: 2. Thermal degradation. Biochemistry Journal, 58, 74-79 (1954).

[13] Sakai Y., Yamato R., Onuma M., Kikuta T., Watanabe M., Nakayama T.: Non-antigenic and low allergenic gelatin produced by specific digestion with an enzymecoupled matrix. Biological and Pharmaceutical Bulletin, 21, 330-334 (1998).

[14] Vajargah S. H., Hosseini H. R. M., Nemati Z. A.: Preparation and characterization of yttrium iron garnet (YIG) nanocrystalline powders by auto-combustion of nitrate-citrate gel. Journal of Alloys and Compounds, 430, 339-343 (2007). DOI: $10.1016 /$ j.jallcom.2006.05.023 
[15] Garskaite E., Gibson K., Leleckaite A., Glaser J., Niznansky D., Kareiva A., Meyer H-J.: On the synthesis and characterization of iron-containing garnets $\left(\mathrm{Y}_{3} \mathrm{Fe}_{5} \mathrm{O}_{12}\right.$, YIG and $\mathrm{Fe}_{3} \mathrm{Al}_{5} \mathrm{O}_{12}$, IAG). Chemical Physics, 323, 204-210 (2006).

DOI: $10.1016 /$ j.chemphys.2005.08.055

[16] Yang Q., Zhang H., Liu Y., Wen Q., Jia L.: The magnetic and dielectric properties of microwave sintered yttrium iron garnet (YIG). Materials Letters, 62, 26472650 (2008).

DOI: $10.1016 /$ j.matlet.2008.01.040

[17] Figueiro S. D., Mallmann E. J. J., Góes J. C., Ricardo N. M. P. S., Denardin J. C., Sombra A. S. B., Fechine P. B. A.: New ferrimagnetic biocomposite film based in collagen and yttrium iron garnet. Express Polymer Letters, 4, 790-797 (2010).

DOI: $10.3144 /$ expresspolymlett.2010.95

[18] Figueiró S. D., Góes J. C., Moreira R. A., Sombra A. S. B.: On the physico-chemical and dielectric properties of glutaraldehyde crosslinked galactomannan-collagen films. Carbohydrate Polymers, 56, 313-320 (2004). DOI: 10.1016/j.carbpol.2004.01.011

[19] Beppu M. M., Vieira R. S., Aimoli C. G., Santana C. C.: Crosslinking of chitosan membranes using glutaraldehyde: Effect on ion permeability and water absorption. Journal of Membrane Science, 301, 126130 (2007).

DOI: $10.1016 /$ j.memsci.2007.06.015

[20] Cheng M., Deng J., Yang F., Gong Y., Zhao N., Zhang X.: Study on physical properties and nerve cell affinity of composite films from chitosan and gelatin solutions. Biomaterials, 24, 2871-2880 (2003).

DOI: $10.1016 / \mathrm{S} 0142-9612(03) 00117-0$

[21] Sarhan A. A., Monier M., Ayad D. M., Badawy D. S.: Evaluation of the potential of polymeric carriers based on chitosan-grafted-polyacrylonitrile in the formulation of drug delivery systems. Journal of Applied Polymer Science, 118, 1837-1845 (2010).

DOI: 10.1002/app.32522

[22] Monteiro O. A. C., Airoldi C.: Some studies of crosslinking chitosan-glutaraldehyde interaction in a homogeneous system. International Journal of Biological Macromolecules, 26, 119-128 (1999).

DOI: $10.1016 / \mathrm{S} 0141-8130(99) 00068-9$

[23] Kasaai M. R.: A review of several reported procedures to determine the degree of $\mathrm{N}$-acetylation for chitin and chitosan using infrared spectroscopy. Carbohydrate Polymers, 71, 497-508 (2008).

DOI: $10.1016 /$ j.carbpol.2007.07.009

[24] Ganji F., Abdekhodaie M. J.: Chitosan-g-PLGA copolymer as a thermosensitive membrane. Carbohydrate Polymers, 80, 740-746 (2010). DOI: $10.1016 /$ j.carbpol.2009.12.021
[25] Peng H., Xiong H., Li J., Xie M., Liu Y., Bai C., Chen L.: Vanillin cross-linked chitosan microspheres for controlled release of resveratrol. Food Chemistry, 121, 23-28 (2010).

DOI: $10.1016 /$ j.foodchem.2009.11.085

[26] Tsai H-S., Wang Y-Z.: Properties of hydrophilic chitosan network membranes by introducing binary crosslink agents. Polymer Bulletin, 60, 103-113 (2008). DOI: $10.1007 / \mathrm{s} 00289-007-0846-\mathrm{X}$

[27] Fechine P. B. A., Silva E. N., de Menezes A. S., Derov J., Stewart J. W., Drehman A. J., Vasconcelos I. F., Ayala A. P., Cardoso L. P., Sombra A. S. B.: Synthesis, structure and vibrational properties of $\mathrm{GdIG}_{\mathrm{X}}: \mathrm{YIG}_{1-\mathrm{X}}$ ferrimagnetic ceramic composite. Journal of Physics and Chemistry of Solids, 70, 202-209 (2009).

DOI: $10.1016 /$ j.jpcs.2008.10.008

[28] Ni N., Zhao K.: Dielectric analysis of chitosan gel beads suspensions: Influence of low crosslinking agent concentration on the dielectric behavior. Journal of Colloid and Interface Science, 312, 256-264 (2007). DOI: $10.1016 /$ j.jcis.2007.03.073

[29] Maier G.: Low dielectric constant polymers for microelectronics. Progress in Polymer Science, 26, 3-65 (2001).

DOI: 10.1016/S0079-6700(00)00043-5

[30] Popielarz R., Chiang C.: Polymer composites with the dielectric constant comparable to that of barium titanate ceramics. Materials Science and Engineering B, 139, 48-54 (2007).

DOI: $10.1016 /$ j.mseb.2007.01.035

[31] Kobayashi Y., Tanase T., Tabata T., Miwa T., Konno M.: Fabrication and dielectric properties of the $\mathrm{BaTiO}_{3}-$ polymer nano-composite thin films. Journal of the European Ceramic Society, 28, 117-122 (2008).

DOI: 10.1016/j.jeurceramsoc.2007.05.007

[32] Fechine P. B. A., Pereira F. M. M., Santos M. R. P., Filho F. P., de Menezes A. S., de Oliveira R. S., Góes J. C., Cardoso L. P., Sombra A. S. B.: Microstructure and magneto-dielectric properties of ferrimagnetic composite $\mathrm{GdIG}_{\mathrm{X}}$ : $\mathrm{YIG}_{1-\mathrm{X}}$ at radio and microwave frequencies. Journal of Physics and Chemistry of Solids, 70, 804-810 (2009).

DOI: 10.1016/j.jpcs.2009.03.009

[33] Marzec E., Pietrucha K.: The effect of different methods of cross-linking of collagen on its dielectric properties. Biophysical Chemistry, 132, 89-96 (2008). DOI: $10.1016 /$ j.bpc.2007.10.012

[34] Valenzuela R.: Magnetic Ceramics. Cambridge University Press, New York (1994).

[35] Rajendran M., Deka S., Joy P. A., Bhattacharya A. K.: Size-dependent magnetic properties of nanocrystalline yttrium iron garnet powders. Journal of Magnetism and Magnetic Materials, 301, 212-219 (2006). DOI: $\underline{10.1016 / j . j m m m .2005 .06 .027}$ 